\title{
ANÁlISE DO PERFIL DAS VÍTIMAS DE ACIDENTES COM MOTOCICLETAS EM SANTARÉM - PARÁ
}

\section{ARTIGO ORIGINAL}

FEIO, Odeize Oliveira ${ }^{1}$

QUARESMA, João Nazareno Nonato ${ }^{2}$

FEIO, Odeize Oliveira. QUARESMA, João Nazareno Nonato. Análise do perfil das vítimas de acidentes com motocicletas em Santarém - Pará. Revista Científica Multidisciplinar Núcleo do Conhecimento. Ano 05, Ed. 03, Vol. 12, pp. 135-150. Março de 2020. ISSN: 2448-0959, Link de acesso: https://www.nucleodoconhecimento.com.br/saude/vitimas-de-acidentes

\section{RESUMO}

O aumento da frota de motocicletas que circulam pela cidade de Santarém tem sido um dos grandes fatores para o aumento de acidentes de trânsito que precisam de atendimento do SAMU. Tem-se, então, como objetivo, identificar o perfil das vítimas de acidentes com motocicletas atendidas pelo Serviço Móvel de Urgência e Emergência no município de Santarém-Pará, no período de 2014 a 2016. Realizou-se o estudo a partir de uma análise estatística de dados no período estabelecido tendo

1 Mestranda em Engenharia de Processos, pelo Instituto de Tecnologia da Universidade do Pará; Especialista em Atenção ao Paciente Critico: UrgênciaEmergência e UTI, pelo Centro Universitário Internacional (UNITER); APHAtendimento Pré - Hospitalar pela UNYLEYA; Enfermagem em Obstetrícia pela FIT/UNAMA; e Terapia Intensiva de Alta Complexidade pela Literatus, em Manaus/AM; Graduada em Enfermagem e Gestão de Organizações de Saúde, pelas Faculdades Integradas do Tapajós-FIT.

2 Doutorado em Engenharia Mecânica. Mestrado em Engenharia Química. Graduação em Engenharia Química. 
por variáveis: perfil das vítimas de acidente, sexo, bairro, período do acidente, tipos de fraturas e tipo de condução automotiva. Os resultados indicaram que o ano com maior ocorrência de acidentes foi em 2015, entre os meses de outubro a dezembro, os indivíduos eram, em sua maioria, do sexo masculino, na faixa etária de 18 a 28 anos e os bairros Centro, Caranazal, Santa Clara e o Santíssimo, registraram um maior quantitativo envolvendo motocicletas no período da tarde, ocasionando, sobretudo, em muitas escoriações, fraturas fechadas e havia poucos registros de óbitos no período estudado. Concluiu-se que esses resultados poderão servir como apoio ao serviço prestado pelo SAMU, sobretudo na forma como deverá ser realizado os primeiros socorros, visto que a utilização desses dados é essencial, uma vez que aponta as prioridades para manejos em saúde, e, até mesmo, para o setor financeiro, identificando as reais necessidades de investimentos na busca por melhorias no atendimento pré-hospitalar.

Palavras-chave: Vítima, acidente de trânsito, motocicleta, SAMU.

\section{INTRODUÇÃO}

As estatísticas têm mostrado que o Brasil é campeão mundial em acidentes de trânsito, o que resulta em muitas mortes sendo até comparáveis a algumas guerras, o que acarreta grandes prejuízos materiais e perdas humanas, afetando a sociedade de forma geral. Assim, como o Brasil e o Estado do Pará, o município de Santarém possui diversos fatores que contribuem para com essa situação, tais como: péssimas condições de ruas, sinalização precária (muitas vezes até inexistentes), aumento do número de veículos, avanço tecnológico que produz veículos cada vez mais potentes e velozes, como, também, a imprudência de condutores e pedestres. A partir desses fatores, verificou-se a necessidade de se realizar um estudo sobre o perfil das vítimas de acidentes com motocicletas atendidas pelo Serviço Móvel de Urgência e Emergência, no município de Santarém-Pará, no período de 2014 a 2016.

Em decorrência da grande quantidade de acidentes com motocicletas no trânsito santareno se faz necessário o estudo de tal problemática. Nesse contexto, indaga-se: Qual é o perfil das vítimas de acidentes com motocicletas atendidas pelo Serviço 
Móvel de Urgência e Emergência no município de Santarém-Pará, no período de 2014 a 2016? Assim sendo, considera-se de grande relevância este estudo, visto que discute o perfil das vítimas de acidentes com motocicletas atendidas pelo Serviço Móvel de Urgência e Emergência no trânsito santareno, na premissa de identificar os indivíduos que estão mais expostos a este tipo de evento, buscando, então, formas para prevenir esta situação. $O$ trabalho tem por objetivo geral identificar o perfil das vítimas de acidentes com motocicletas atendidas pelo Serviço Móvel de Urgência e Emergência no município de Santarém-Pará, no período de 2014 a 2016.

Os específicos, por sua vez, visam descrever o atendimento de emergência aos acidentados no trânsito, discorrer sobre o SAMU e sua relevância para o atendimento pré-hospitalar e verificar os dados sobre as vítimas de acidente com motocicletas atendidas pelo SAMU em Santarém no período pré-definido. Este estudo tem a pretensão de contribuir com novos conhecimentos para a saúde, trazendo, para tanto, insumos para o desenvolvimento de novas reflexões sobre as vítimas de acidentes com motocicleta no Município de Santarém, buscando destacar a relevância do atendimento dos profissionais do SAMU, e, ainda, pretende-se discutir a possibilidade de mudanças futuras na realidade do atendimento em saúde, uma vez que conhecendo o perfil dessas vítimas e os tipos de lesões ocasionados por esse tipo de acidente, pode-se criar ações mais eficazes, viabilizando-se a melhoria da qualidade do cuidado e do atendimento do acidentado.

\section{METODOLOGIA}

Este estudo teve o enfoque empírico analítico, de caráter quantitativo, retrospectivo e descritivo de dados coletados na Secretaria Municipal de Saúde de Santarém SEMSA, no Estado do Pará. A pesquisa também foi de caráter documental, visto que foram analisados os relatórios dos atendimentos às vítimas de acidentes automobilísticos em Santarém no período de 01/01/2014 a 31/12/2016. Os resultados foram classificados a partir do total de acidentes com motocicletas, meses de ocorrência, faixa etária, sexo, local do acidente, horário, veículos envolvidos e tipo de lesão. 
Os dados foram coletados mediante a digitação e tabulação por meio do programa EPDATA 3.5 e as tabulações e análises ocorreram no Microsoft Word e Excel/Tabwin 3.2, facilitando a elaboração, estruturação e análise das tabelas e gráficos gerados. Foi utilizado o programa Exce/ versão 2010 e as fórmulas concernentes, o que gerou, automaticamente, o cálculo do percentual relativo ao número de respostas obtidas para cada item, facilitando, dessa forma, a confecção das tabelas e gráficos para posterior análise. Para a análise, utilizou-se o método analítico-descritivo com base quantitativa para tabulação deles.

\section{RESULTADOS E DISCUSSÃO}

Ao analisar o período estabelecido para a construção deste estudo, verificou-se que ocorreram 4.805 acidentes com motocicletas entre 2014 a 2016, sendo que o ano de 2015 foi o período no qual mais ocorreram mais acidentes, com 1.575 casos de motociclistas acidentados atendidos pelo SAMU. Em seguida, foi o ano de 2016, com 1.321 casos registrados. Já o ano de 2014 obteve 1.189 casos registrados, conforme descrito na figura 1.

Figura 1 - Total de atendimentos do SAMU às vítimas de acidentes de motocicleta, no período de 2014 a 2016

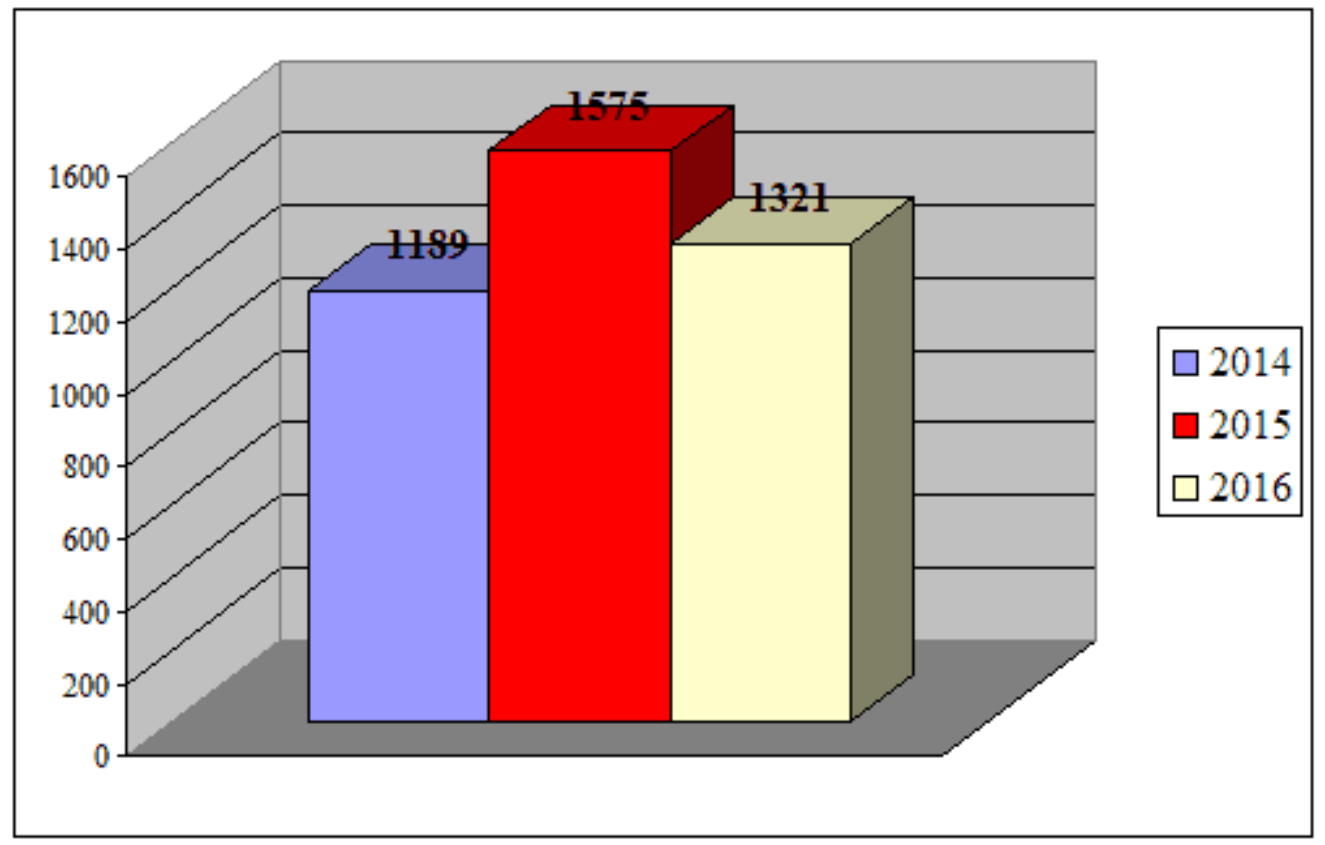


A realidade ora ressaltada reforça a necessidade de haver serviços de urgência nas cidades do interior do Estado, capazes de prestar um cuidado de qualidade às vítimas, sem que seja necessária à sua transferência para a capital do Estado. Pode-se observar que, não necessariamente, à medida que o ano aumenta, os acidentes aumentam. 2015 foi o maior de todos, e, talvez, isto deve estar relacionado com o tamanho da frota que foi maior em 2015. Na pesquisa realizada por Santos (2017), os dados são diferentes dos encontrados em Santarém, visto que o aumento de acidentes envolvendo motocicletas em Brasília foram maiores no ano de 2016. Segundo Oliveira e Sousa (2003), nas últimas décadas, no Brasil, tem ocorrido um aumento crescente no número de acidentes envolvendo motocicletas, veículo que vem ganhando, cada vez mais, a aceitação e a aprovação da população, por ser ágil, econômico e de custo reduzido.

Souza (2012) ressalta que a proporção de feridos nos acidentes de moto é maior do que naqueles ocorridos nos demais acidentes de trânsito de veículo a motor, devido a grande vulnerabilidade de seus condutores. Para ele não há proteções similares àquelas dos ocupantes de veículos de quatro rodas. Em análise mensal referente aos atendimentos dos acidentados com motocicletas em Santarém, no período de 2014 a 2016, verificou-se que os meses de maior ocorrência de acidentes foram no ano de 2015, principalmente nos meses de dezembro, com 172 casos registrados; março, com 155 casos registrados; outubro, com 154 casos registrados e novembro, com 150 casos registrados. Já no ano de 2016, que também teve alto índice, os meses com maiores índices foram fevereiro, com 136 casos; janeiro, com 134 casos e julho, com 127 casos. Já o ano de 2014, que teve números menores de ocorrências registradas no SAMU, apresentou maior índice no mês de outubro, com 132 casos registrados; julho, com 125 casos registrados e novembro, com 123 casos registrados, conforme descrito na figura 2 . 
Figura 2 - Quantidade mensal de atendimentos do SAMU de acidentes com motocicletas em Santarém, no período de 2014 a 2016

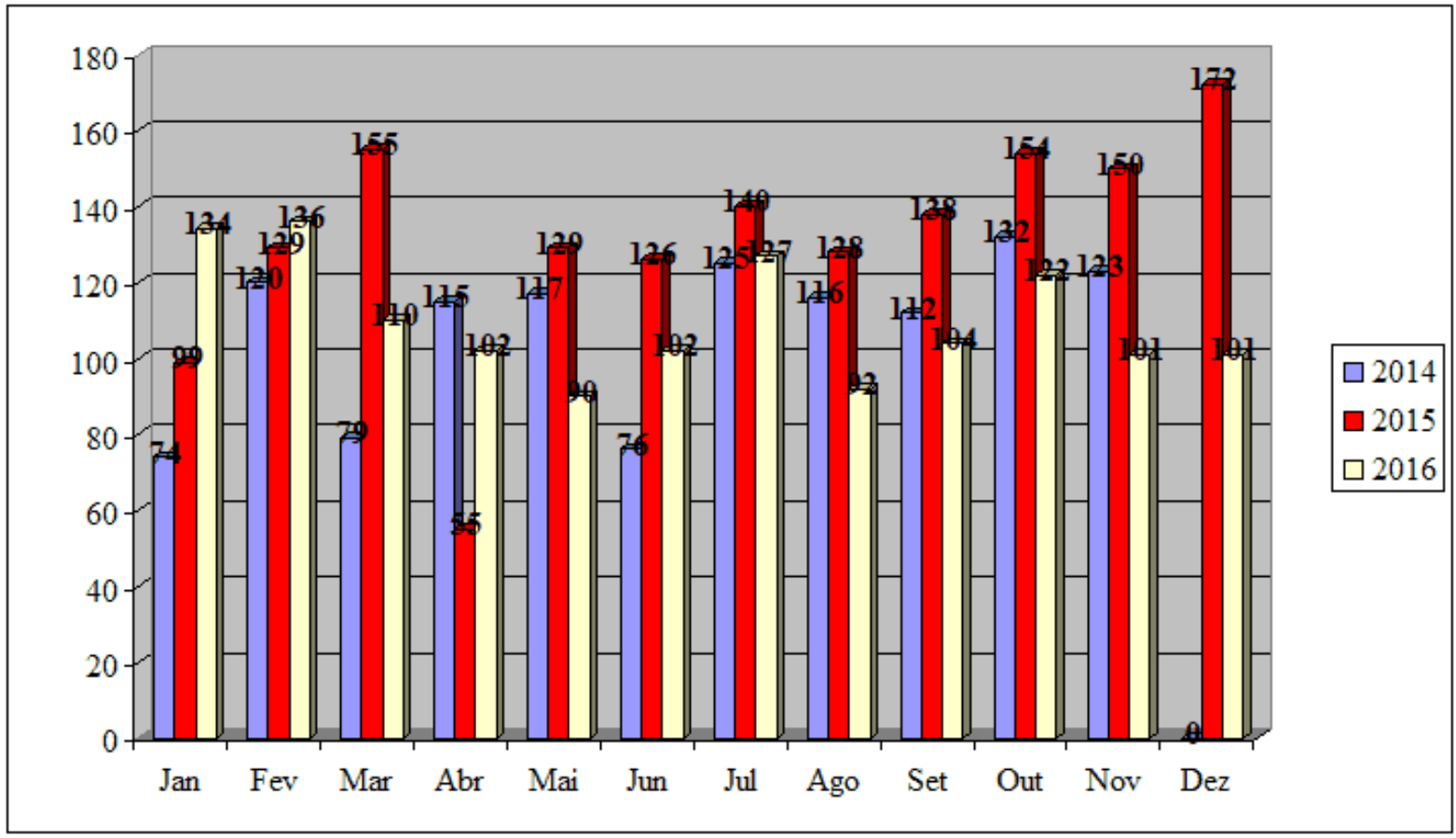

Fonte: SEMSA, 2018

Pode-se observar que no ano de 2015, em que houve maior ocorrência de acidentes com motocicletas, a maioria dos meses desse ano foram os que mais apresentaram estatísticas de acidentes, destacando-se, principalmente, o mês de dezembro, em que a ocorrência foi a maior de todo período, provavelmente devido ao período de festas. Gabani (2011), em seu estudo, verificou a maior ocorrência de acidentes com motocicletas nos meses de novembro e dezembro e como menor índice de vítimas, em fevereiro. No estudo de Souza (2012), por sua vez, a maior ocorrência foi em abril. Na pesquisa de Silva et al (2015) observou-se a maior prevalência de acidentes com motocicletas nos meses de maio, março e janeiro. Porém, no estudo de Santos (2017), por conseguinte, houve aumento de acidentes nos meses de fevereiro a julho de 2016.

Quanto à faixa etária dos acidentados atendidos pelo SAMU, no período de 2014 a 2016, verificou-se que os indivíduos na faixa etária de 18 a 28 anos são os que mais sofrem acidentes com motocicletas em Santarém, sendo que no ano de 2015 foram registrados 824 casos, já em 2016, 664 casos e em 2014, 641 casos. Em seguida, 
tem-se os indivíduos na faixa etária de 29 a 38 anos, registrando-se 423 casos de acidentes em 2015; em 2016, 371 casos e em 2014, 298 casos. A faixa etária em que houve menos registros de acidentes com motocicletas em Santarém foi de indivíduos com 59 anos e acima, sendo que, em 2015, houve 49 casos registrados; em 2016, 39 casos e em 2014, 29 casos registrados. Os indivíduos da faixa etária de 39 a 48 anos só apresentaram índices de acidentes em 2014, com 178 casos registrados, conforme descrito na figura 3.

Figura 3 - Faixa etária dos indivíduos atendidos pelo SAMU por acidentes com motocicletas em Santarém, no período de 2014 a 2016

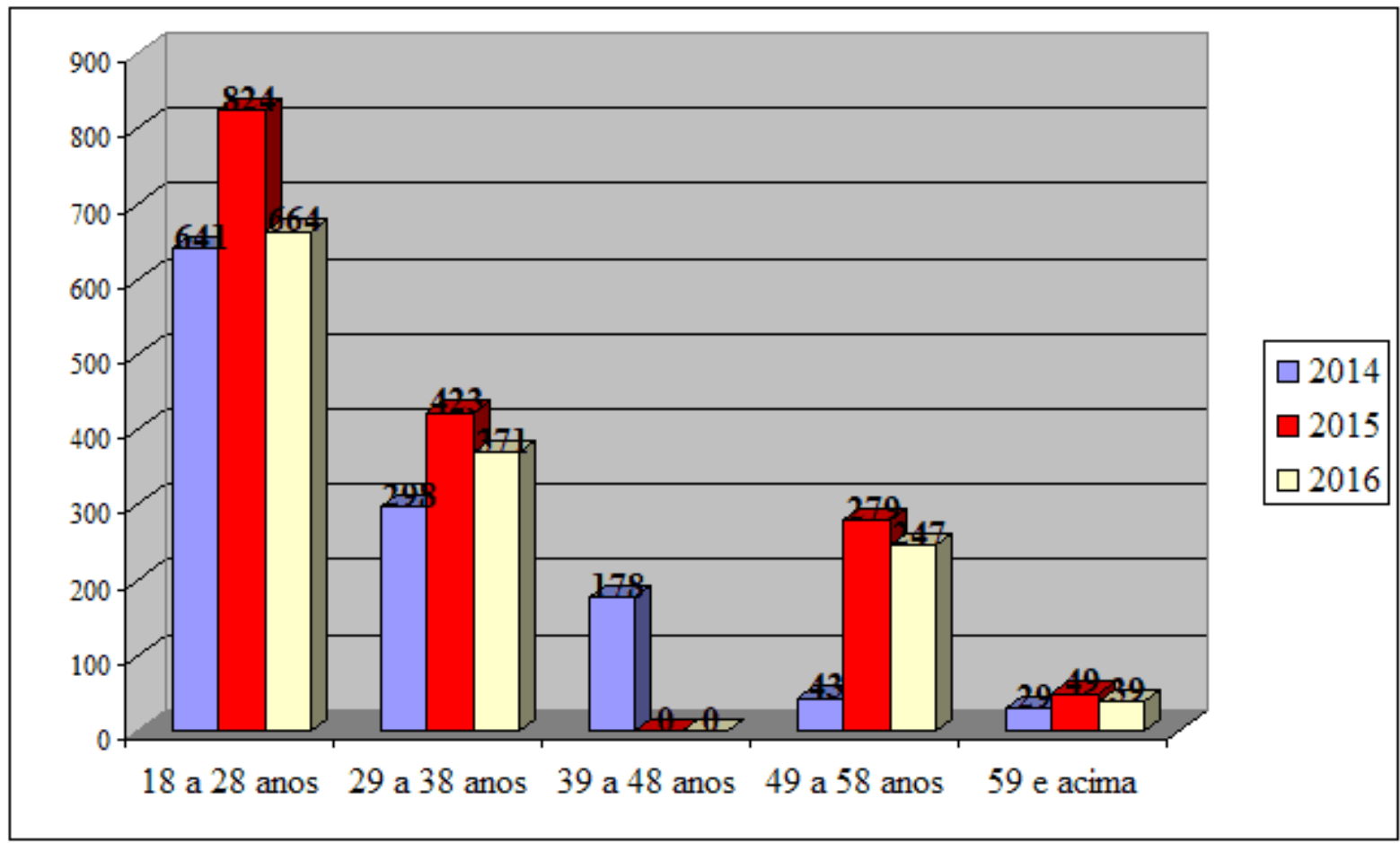

Soares et al (2015) verificaram, em sua pesquisa realizada em 2010, que a maior incidência de acidentes com motocicletas ocorreu entre jovens com idade média de 28 anos, corroborando com os dados encontrados no estudo em Santarém. No estudo de Amorim et al (2012) houve predominância de indivíduos com média de idade de 37,4 anos. Nos estudos de Golias e Caetano (2013), Barbosa et al (2014) e Souza (2012) também se relatou maior predominância de indivíduos jovens, na faixa etária entre 20 e 29 anos. Esses autores ressaltam que o fato de utilizarem a motocicleta no 
mercado de trabalho explicaria o predomínio etário. Esses dados mostram, ainda, a crescente participação de adultos jovens nas estatísticas dos acidentes de trânsito, em especial os que envolvem motocicleta.

A maior prevalência de acidentes nessa faixa etária traz graves consequências sócioeconômicas para a sociedade, uma vez que são jovens em plena idade reprodutiva que, em decorrência do acidente, interrompem suas atividades, deixam de gerar renda e produção ao sistema econômico e ocasionam custos ao sistema de saúde com internações hospitalares e reabilitações, além de causar sofrimento à família, gerando, ainda, incapacidades físicas e sequelas, tornando-se, assim, um complexo problema de saúde pública (BARBOSA et al, 2014). Quanto ao sexo dos indivíduos acidentados que receberam atendimento do SAMU no triênio 2014-2016, verificou-se que o sexo masculino foi o das maiores vítimas desse tipo de acidente nos três anos pesquisados.

Dessa forma, considerando o contexto investigado e, consequentemente, analisado por este estudo, verificou-se, então, que, em 2015, houve, aproximadamente, 1.108 casos registrados de indivíduos do sexo masculino atendidos pelo SAMU por esse tipo de acidente; em 2016 foram 984 casos registrados e em 2014, 798 casos registrados. Ainda sobre o mesmo contexto, identificou-se que os indivíduos do sexo feminino também já estão presentes nas estatísticas, ainda que de forma menos frequente. Em 2015, o ano de maior ocorrência, foram registrados 467 atendimentos a vítimas do sexo feminino por acidentes com motocicletas em Santarém; em 2014 houve 391 atendimentos e em 2016, 337 casos registrados, conforme descrito na figura 4. 
Figura 4 - Sexo dos pacientes atendidos pelo SAMU por acidente com motocicletas em Santarém, no período de 2014 a 2016

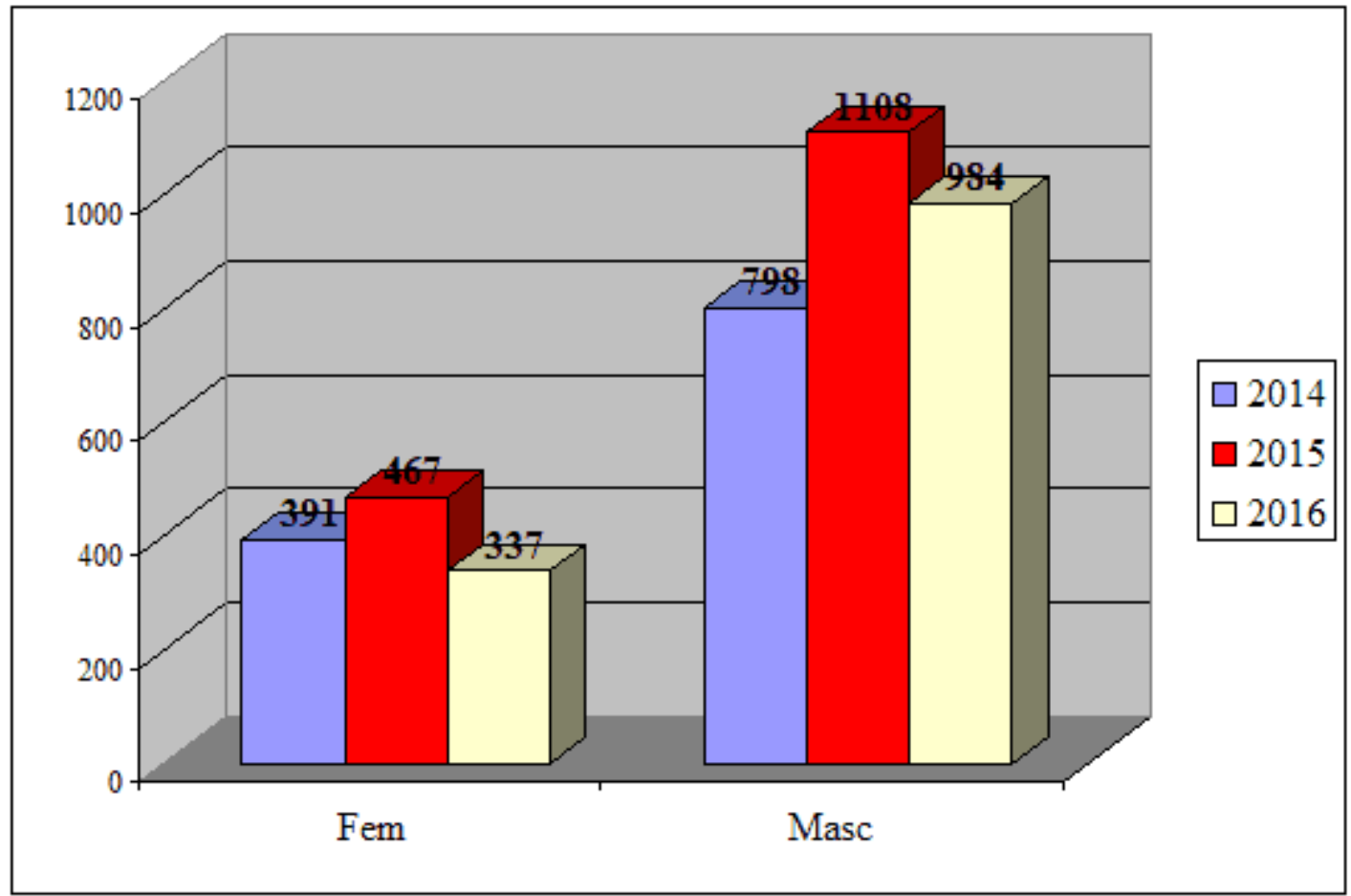

A maior proporção de vítimas desse sexo pode estar relacionada com uma maior exposição assim como com a maior utilização desse tipo de veículo, o que faz com que se compreenda a alteração da proporção aqui observada ao se analisar a situação por gênero, considerando-se que, em Santarém, ainda é reduzida a presença de mulheres pilotando esse veículo. Soares et al (2015) realizaram uma pesquisa sobre os acidentes de trânsito, com maior enfoque em acidentes de motocicletas, atendidos em um serviço de emergência situado no município de Picos (PI), identificando que, entre os 80 participantes da amostra, $88,7 \%$ eram do sexo masculino. Esses dados são corroborados por Amorim et al (2012), Macêdo e Oliveira (2012), entre outros.

Golias e Caetano (2013) ressaltam que o homem tende a se considerar mais competente que a mulher na direção, e, por isso, tem menor percepção de riscos enquanto dirigem; além de serem mais agressivos, fazendo manobras arriscadas, ao contrário da mulher, que é mais prudente, correndo menos, além de buscarem maior segurança nas manobras. Nesse contexto, percebe-se que a superioridade numérica 
se deve, segundo Golias e Caetano (2013), em relação às características de gênero, afirmam, e, por sua vez, no mesmo estudo, ilustram e discorrer acerca dos possíveis efeitos relacionados aos padrões socioculturais que são cristalizados para o sexo masculino, já que não existe um fator biológico que determina essa predisposição.

Quanto ao local de acidente, devido a grande quantidade de bairros existentes em Santarém, escolheu-se apresentar os bairros nos quais é mais frequente o número de acidentes, verificando-se que a maior ocorrência de acidentes com motocicletas, no período de 2014 a 2016, foi no bairro Centro, principalmente no ano de 2015, com 64 casos registrados, seguido do bairro Caranazal, que apresentou maior índice em 2016, com 72 casos registrados. Outro bairro de grande incidência de acidentes com motocicletas é o Santa Clara, com grandes ocorrências em 2015 e 2016, com 53 casos registrados, em cada ano. $\mathrm{O}$ bairro Santíssimo também apresentou grande índice, com maior ocorrência no ano de 2016, com 53 casos registrados, conforme descrito na figura 5 .

Figura 5 - Local dos acidentes com motocicletas atendidos pelo SAMU em Santarém, no período de 2014 a 2016

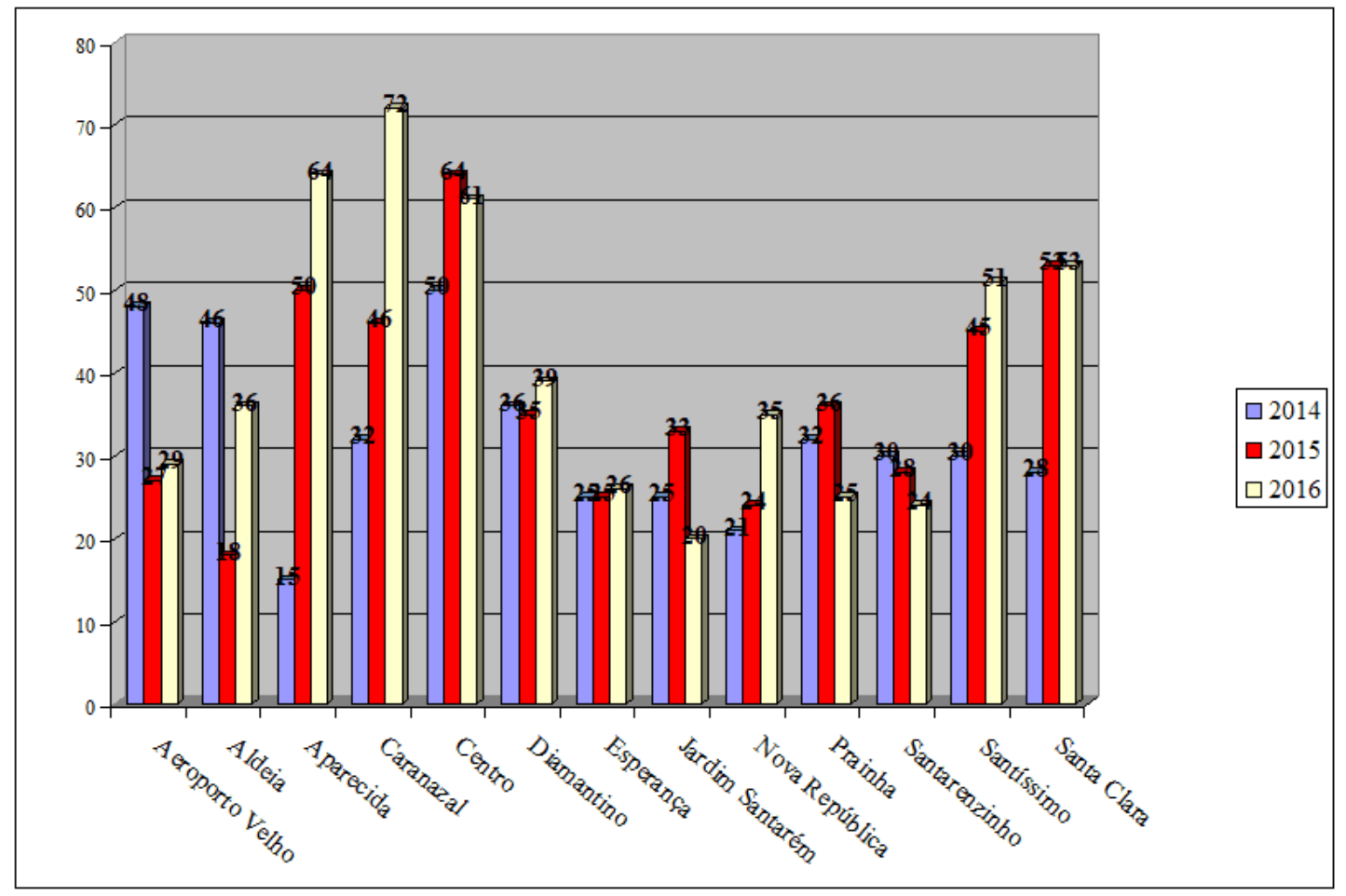


Observa-se que os bairros em que há maior ocorrência de acidentes envolvendo motocicletas são os mais populosos e que possuem melhores vias de acesso, com ruas mais largas e asfaltadas. Dados semelhantes foram encontrados no estudo de Santos (2017), que destacou maior ocorrência desse tipo de acidente em bairros com maior índice de habitantes, porém, com ruas estreitas e mal sinalizadas. Quanto aos veículos envolvidos nos acidentes com motocicletas atendidos pelo SAMU em Santarém, verificou-se que a maior ocorrência são acidentes de motocicleta com carro, sendo que, no ano de 2015, houve 725 casos registrados; em 2016, 669 casos registrados e, em 2014, 542 casos registrados.

Outra forma mais frequente de acidentes com motocicletas são as derrapagens que ocasionam quedas do motociclista e do passageiro, sendo que o ano em que houve maior índice desse tipo de ocorrência foi em 2014, com 354 casos registrados; em 2015, foram registrados 213 casos e, em 2016, 171 casos. Acidentes de moto com moto também foram frequentes, principalmente em 2016, com 365 casos registrados; em 2015, foram registrados 300 casos, e, em 2014, 249 casos. Acidentes de moto com caminhão ou ônibus foram os menos frequentes no período pesquisado, conforme descrito na figura 6 .

Figura 6 - Tipos de veículos envolvidos nos acidentes atendidos pelo SAMU em Santarém, no período de 2014 a 2016

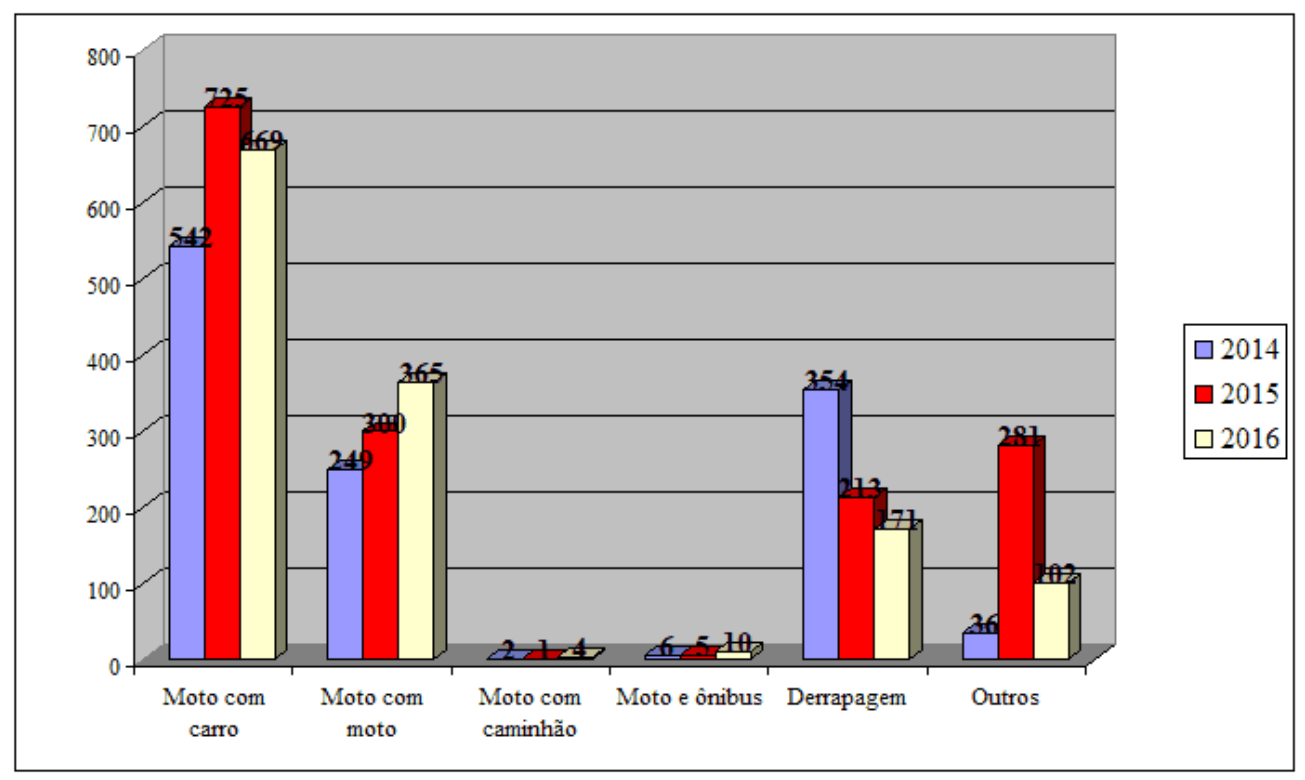


Comparando-se os resultados obtidos com os trabalhos de Gabani (2011), Golias e Caetano (2013), Silva et al (2015), é possível fazer algumas considerações. Para Barbosa et al (2014), as colisões de motocicletas com carros foram as mais frequentes, seguidas de derrapagens que ocasionam as quedas. Este tipo de evento tem a possibilidade de estar relacionado com a imprudência, excesso de velocidade e mesmo com o abuso de álcool e outras drogas, além da inexperiência de muitos condutores. Quanto ao horário dos acidentes com motocicletas atendidos pelo SAMU em Santarém, observou-se que o maior índice de acidentes foi no período diurno, principalmente durante a tarde, sobretudo em 2015, com 507 casos registrados; em 2016 foram registrados 435 casos, e, em 2014, 382 casos.

A diferença entre manhã e tarde é pouca, sendo que no horário que apresentou maior ocorrência em 2015 contou com 512 casos registrados; em 2016, 442 casos registrados, e, em 2014, 319 casos registrados. No período noturno, apesar de haver muitas ocorrências, elas ocorrem até as 23 horas, sendo que em 2015 foram registrados 424 casos de acidentes com motocicletas nesse horário; em 2016, 357 casos, e, em 2014, 350 casos. Já no horário da madrugada, a frequência de acidentes com motocicletas é mais reduzido, sendo que o ano de 2014 foi o que mais apresentou casos de acidentes nesse horário, com 138 registros; em 2015 foram 132 casos registrados, e, em 2016, 87 casos, conforme descrito na figura 7 .

Figura 7 - Horário de acidentes com motocicletas atendidos pelo SAMU em Santarém, no período de 2014 a 2016

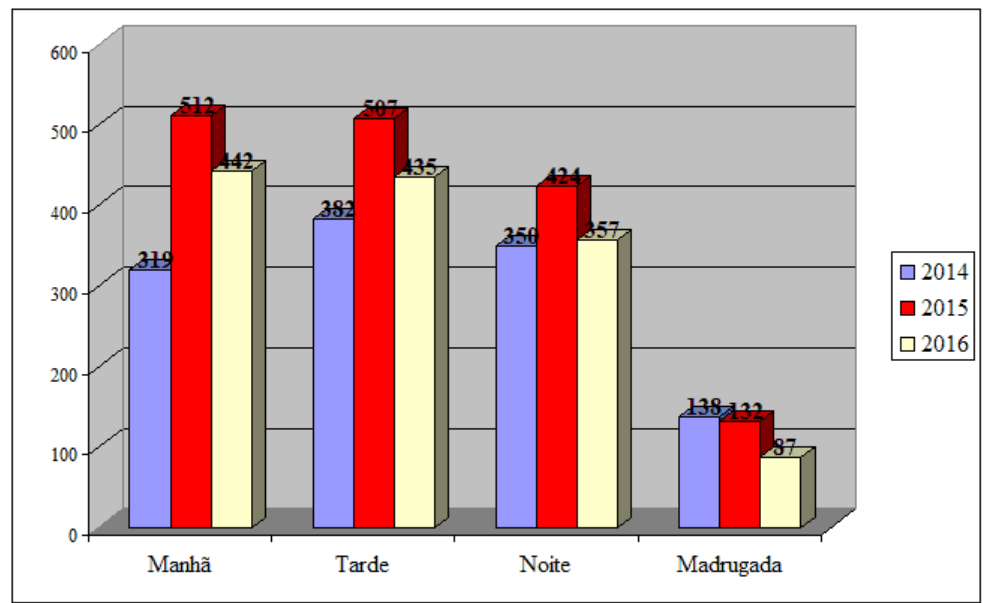


Gabani (2011) relata, em seu estudo, a prevalência de acidentes com motociclistas no período da noite e da manhã, provavelmente devido a ser o período em que os motociclistas estão trabalhando. Golias e Caetano (2013) detectaram que a maior ocorrência de acidentes foi no período vespertino e noturno, enfatizando que o período em que ocorre acidentes de moto-moto é o noturno. Os autores consideram que a prevalência de acidentes no período noturno se deve à visibilidade limitada pelo alcance dos faróis, falta de sinalização de veículos parados, excesso de velocidade, desrespeito à sinalização e uso de álcool e outras drogas. No estudo de Soares et al (2015) foi observada a maior ocorrência de acidentes com motocicletas no período vespertino, seguido do período noturno, corroborando os dados encontrados em Santarém.

Quanto ao tipo de lesão dos acidentados, observou-se que a grande maioria das vítimas de acidente com motocicletas sofreu escoriações, sendo que, em 2015, houve 1.238 registros desse tipo de lesão; em 2016, foram 1.000 casos registrados, e, em 2014, 629 casos registrados pelo SAMU. Outro tipo de lesão frequente é a fratura fechada, sendo que em 2016 foram registrados 160 casos de vítimas com esse tipo de lesão; em 2015, 132 casos registrados, e, em 2014, 128 casos registrados pelo SAMU. Os traumas nos membros também são frequentes, sendo que, em 2014, houve 151 casos de traumas nos membros inferiores e nos membros superiores foram 118 casos registrados nesse mesmo ano. Já os casos de óbito foram poucos, registrando-se 4 casos em 2015 e 2 casos em 2016, conforme descrito na figura 8. 
Figura 8 - Tipos de lesão ocasionadas por acidentes com motocicletas atendidos pelo SAMU em Santarém, no período de 2014 a 2016

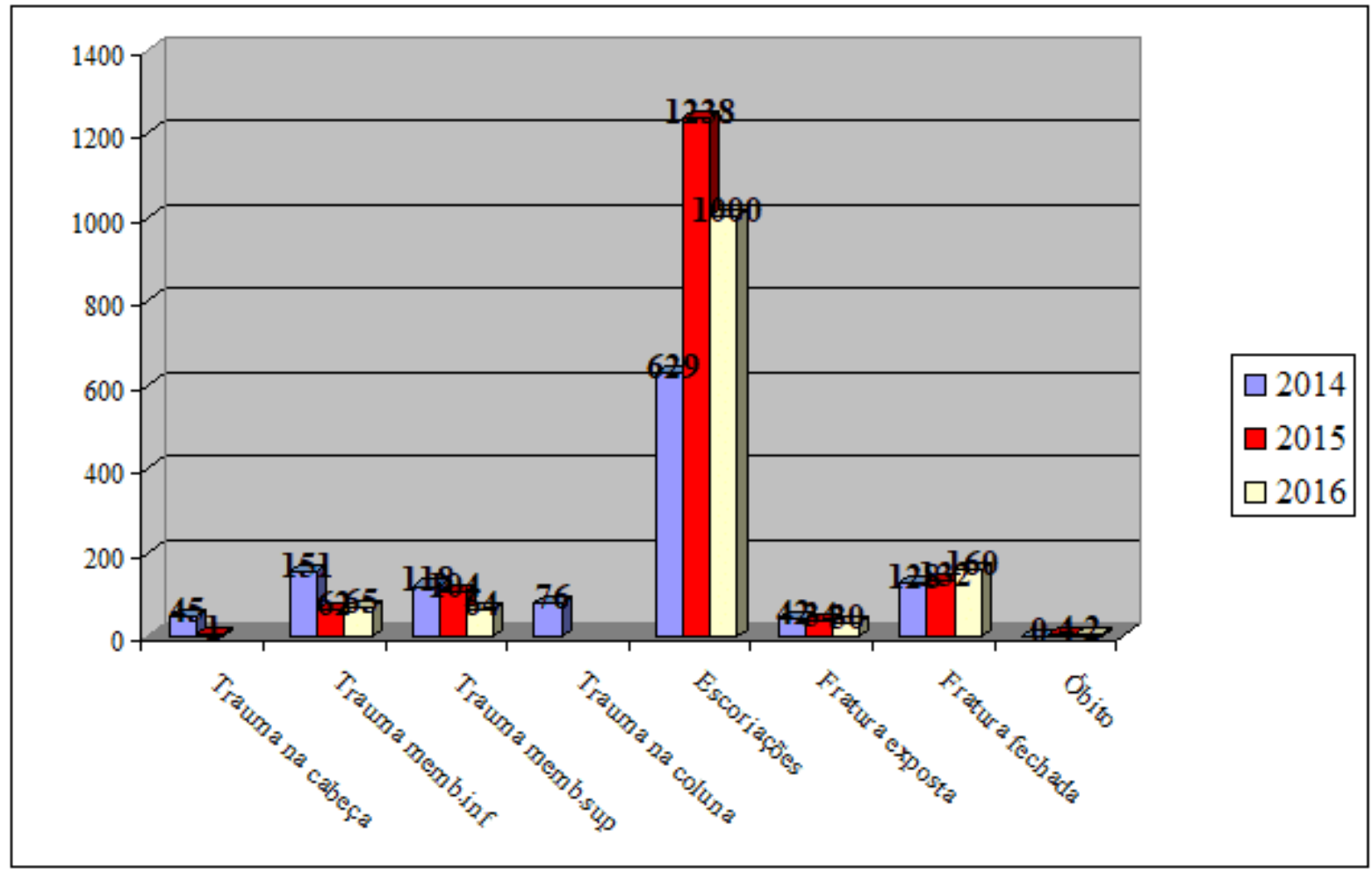

As escoriações são o tipo de lesão mais frequente em condutores de motocicletas, conforme se pôde observar na maioria dos estudos aqui analisados, como os de Gabani (2011), Souza (2012), Santos (2017), Golias e Caetano (2013) e Barbosa et al (2014). Eles ressaltam que determinar o tipo de lesão é de grande relevância para os atendentes do SAMU, pois auxilia a ter clareza acerca da gravidade do acidente, para, assim, direcionar as medidas de intervenção. Os autores também relatam que o politraumatismo é mais frequente em colisões de moto e carros, pois o condutor é lançado em grande distância, conforme a velocidade do impacto. Silva et al (2015) ressaltam que o trauma em acidentes de trânsito está classificado como a primeira causa de morte entre indivíduos na faixa produtiva de 18 a 44 anos de vida. Os autores, ainda, reforçam que os indivíduos que não morrem no acidente passam a conviver com alguma sequela em decorrência de alguma causa externa, e, na maioria das vezes, por acidentes que poderiam ser evitados. 


\section{CONSIDERAÇÕES FINAIS}

Os resultados demonstraram que a frota de motocicletas nesta cidade é elevado e devido a vários fatores e ela é a maior causa de acidentes de trânsito em Santarém, como se observou na pesquisa. Analisando o triênio 2014-2016, observou-se que a maior ocorrência de acidentes de trânsito com motocicletas, em que as vitimas foram atendidas pelo SAMU, foi em 2015, com 1.575 casos registrados pela Secretaria Municipal de Saúde de Santarém, sendo que os meses de maior ocorrência foram março, outubro, novembro e dezembro, ressaltando que, neste último mês, alcançou-se o maior índice do período. Quanto ao perfil das vítimas, pôde-se verificar que são indivíduos do sexo masculino, na faixa etária de 18 a 28 anos, considerada pelos autores como a faixa etária economicamente ativa e que, normalmente, são sujeitos que utilizam a motocicleta como meio de transporte ou mesmo de trabalho.

Ao analisar os locais dos acidentes, observou-se maior frequência nos bairros mais populosos de Santarém, como Centro, Caranazal, Santa Clara e o Santíssimo. Esses bairros, além de serem mais populosos, também possuem muitas vias de acesso, em bom estado de conservação, e, também, é onde estão localizadas algumas das faculdades e grande colégios da cidade, o que pode ser um dos fatores para a grande quantidade de acidentes nesses locais. Observando os resultados, pôde-se perceber que a maior frequência dos acidentes ocorre entre motocicleta e carro, além de derrapagens que originam as quedas dos condutores e passageiros. Em Santarém, o horário dos acidentes é, geralmente, o período diurno, principalmente o período da tarde, ocasionando muitas escoriações nos condutores de motocicletas e em seus passageiros.

As fraturas fechadas também são frequentes nesse tipo de acidente em Santarém. Um fato relevante foi observado no triênio 2014-2016: houve poucos casos de óbito por acidentes de trânsito com motocicletas em Santarém, havendo mais ocorrências em 2015, com 4 casos registrados. Assim, esses resultados podem ser utilizados de forma confiável para o serviço do SAMU, haja vista a grande quantidade de atendimentos que ele realiza, de forma rápida e segura, possibilitando o resgate da vítima em tempo hábil e com um atendimento de qualidade. 
Nesse contexto, concluiu-se que os resultados apresentados no presente estudo apontam para a necessidade de medidas mais eficazes para redução dos acidentes com motocicletas, tendo em vista a ampliação da frota desse tipo de veículo em Santarém, evidenciando a necessidade de ações voltadas para a educação no trânsito e maior fiscalização dos condutores. É necessária, também, a realização de novos estudos que preencham lacunas do conhecimento e venham colaborar no combate a este importante agravo à saúde pública. Como sugestão, acredita-se que o mesmo estudo poderia ser realizado em outras cidades da Região Amazônica, região na qual o número de indivíduos que utilizam motocicletas é muito grande, visando obter dados sobre o perfil dos acidentados, para, assim, poder definir estratégias para redução desses acidentes nas cidades dessa região.

\section{REFERÊNCIAS}

AMORIM, C. R. et al. Acidentes de trabalho com mototaxistas. Revista Brasileira de Epidemiologia, v. 15, n. 1, p. 25-37, 2012.

BARBOSA, M. Q. et al. Acidente Motociclístico: Caracterização das Vitimas Socorridas pelo Serviço de Atendimento Móvel de Urgência (SAMU). Revista Brasileira de Ciências da Saúde, v. 18, n. 1, p. 3-10, 2014.

\section{GABANI, F. L. Motociclistas atendidos por serviços de atenção pré-hospitalar em}

Londrina: Características dos acidentes e das vítimas em 1998 e 2010. 2011. 169 f. Dissertação (Mestrado em Saúde Coletiva) - Universidade Estadual de Londrina, Centro de Ciências da Saúde, Programa de Pós-Graduação em Saúde Coletiva, Londrina, 2011.

GOLIAS, A. R. C.; CAETANO, R. Acidentes entre motocicletas: análise dos casos ocorridos no estado do Paraná entre julho de 2010 e junho de 2011. Ciência \& Saúde Coletiva, v. 18, n. 5, p. 1235-1246, 2013. 
OLIVEIRA, N. L. B.; SOUSA, R. M. C. Diagnóstico de lesões e qualidade de vida de motociclistas, vítimas de acidente de trânsito. Revista Latino-Americana de Enfermagem, v. 11, p. 749-756, 2003.

SANTOS, M. da. S. Serviço de Atendimento Móvel de Urgências-SAMU/DF: Atendimentos relacionados aos acidentes de motocicletas. 2017. 43 f. Trabalho de Conclusão de Curso (Graduação em Saúde Coletiva e Bacharel Sanitarista) Universidade de Brasília-UnB, Brasília, 2017.

SILVA, F. da. et al. Vítimas de trauma por acidente de moto atendidas em serviço móvel de urgência. Revista de enfermagem UFPI, v. 4, n. 3, p. 71-78, 2015.

SOARES, L. S. et al. Caracterização das vítimas de traumas por acidente com motocicleta internadas em um hospital público. Revista de enfermagem UERJ, v. 23, n. 1, p. 15-21, jan/fev. 2015.

SOUZA, P. de. Acidentes de motocicleta: caracterização das vítimas socorridas pelo SAMU de Braço do Norte-SC. 2012. 32 f. Monografia (Especialista em Assistência de Enfermagem em Urgência e Emergência) - Universidade do Extremo Sul CatarinenseUNESC, Criciúma, 2012.

Enviado: Março, 2020.

Aprovado: Março, 2020. 